\title{
Aquazol as a binder for retouching paints. An evaluation through analytical pyrolysis and thermal analysis
}

\author{
J. La Nasa ${ }^{1}$, F. Di Marco ${ }^{1}$, L. Bernazzani ${ }^{1}$, C. Duce ${ }^{1}$, A. Spepi ${ }^{1}$, V. Ubaldi ${ }^{2}$, S. Orsini $^{1}$, S. \\ Legnaioli $^{3}$, I. Degano ${ }^{1}$, M.R. Tiné ${ }^{1}$, D. De Luca ${ }^{2}$, F. Modugno ${ }^{1}$ \\ ${ }^{1}$ Department of Chemistry and Industrial Chemistry, University of Pisa, Italy; \\ ${ }^{2}$ Department of Pure and Applied Sciences, Conservation and Restoration of Cultural Heritage, \\ University of Urbino Carlo Bo, Italy; \\ ${ }^{3}$ Institute of Chemistry of Organometallic Compounds CNR-ICCOM, Pisa Italy
}

\section{Abstract}

Aquazol poly (2-ethyl-oxazoline) is a tertiary aliphatic amide, with physical and chemical properties that are exploited in a variety of ways, from pharmaceutical applications to the conservation of cultural heritage. In this study, we evaluated the use of Aquazol as a new binder for retouching paint in the restoration of artworks.

Aquazol 500 admixed with various formulations of organic red pigments was used to prepare paint replicas which were artificially aged and investigated by a multi-analytical approach based on analytical pyrolysis coupled with gas chromatography and mass spectrometry (Py-GC/MS), and thermogravimetry (TG), complemented by FTIR and LIBS spectroscopy. This is the first study on the ageing phenomena of Aquazol 500 using analytical pyrolysis and thermogravimetric analysis. The influence of the pigments' components on the pyrolysis behavior of Aquazol was also investigated.

The paint replicas did not show significant modifications during artificial ageing. This thus highlights the optimal properties of Aquazol 500 as a binder for retouching, in addition to its already established suitability as a filler or consolidant in the restoration of artifacts. Interestingly, when Aquazol 500 is used in formulations containing organic pigments, Aquazol-pigment interactions are observed, strongly depending on the pigment used.

\section{Keywords}

Aquazol, Retouch paint, Organic pigments, Analytical pyrolysis coupled with gas chromatography and mass spectrometry (Py-GC/MS), Thermogravimetry (TG). 


\section{Introduction}

The technology transfer from the polymer industry to conservators and conservation scientists is of paramount importance in the conservation of artworks. The conservation of paintings is a delicate field of material science, where tailored solutions based on advances in polymer science and on new commercial synthetic macromolecules can be exploited to formulate innovative consolidants, binders, varnishes or coatings. It is thus important to assess whether the newly-developed material has improved features compared to those available in terms of stability, compatibility and reversibility.

This study evaluates the use of polymer poly (2-ethyl-oxazoline) as a new binder for retouching paint in the restoration of paintings.

Poly (2-ethyl-oxazoline) or PEOX was first marketed in 1977 with the commercial name Aquazol, by the Dow Chemical Company [1]. It is now produced by Polymer Chemistry Innovations in four ranges of molecular weight: $5000 \mathrm{~g} / \mathrm{mol} ; 50000 \mathrm{~g} / \mathrm{mol} ; 200000 \mathrm{~g} / \mathrm{mol}$; and $500000 \mathrm{~g} / \mathrm{mol}$ (Aquazol®) 5, 50, 200 and 500 respectively) [2]. Aquazol is a tertiary aliphatic amide, with physical and chemical properties, which are now being exploited for an increasing variety of ways, from pharmaceutical applications to the conservation of the cultural heritage [3], [4], [5], [6], [7], [8], [9], [10], [11]. Aquazol's physico-chemical properties were first described in 1986 by T.T Chiu et al. [12], in terms of the composition, polymerization mechanism and properties. The wide range of solubilities in several polar and medium polar solvents including water is one of its key features in several applications. This makes Aquazol a versatile material for use in the cultural heritage, since if necessary it can be removed after application thus ensuring a good reversibility of the conservation treatments.

Aqualzol was proposed as a consolidant for the first time by R. Wolbers et al. in the early 1990s [5]. The properties of the polymer have subsequently been investigated in terms of $\mathrm{pH}$, colour and viscosity measurements, tensile strength and re-solubilization tests, FTIR spectroscopy, sizeexclusion chromatography (SEC) and thermogravimetry (TG), thus suggesting a good optical and chemical stability of the material [12]. Stress/strain curves generated as a function of relative humidity $(\mathrm{RH})$ variations have shown that Aquazol films maintain a good elasticity when exposed to different RH conditions. In addition, Aquazol is a green material [3] and is compatible with other polymers to obtain mixtures with modulated properties. The few analytical studies described in the literature include its characterization by pyrolysis coupled with gas-chromatography (Py-GC/MS) [13], which have been shown to be suitable in investigating its molecular structure.

Conservators have tested and applied Aquazol as a weak adhesive [9], [14], [15], as a consolidant and filler [8], [16], [17], [18], [19], [20], and as an ingredient in the preparation of bole for the application of gilding [21]. However, to date it has only been tested on a few painted surfaces [22]. Several 
potential applications of Aquazol as a conservation material are currently under investigation, such as its use as a consolidant for unvarnished painted surfaces, in combination with $\mathrm{TiO} 2$ nanoparticles [23].

The properties described above along with the data available in the literature also suggest that Aquazol is a suitable candidate for use as a binder for reversible paints for retouching during the conservation of paintings. Retouching a painting is one of the most common and critical conservation practices, where the reversibility of the applied retouching materials is key in guaranteeing the ethical acceptability of the intervention, which entails removal and re-treatment. The most common retouching paints are today based on Arabic gum as a paint binder, and thus are not suitable for watersensitive painted surfaces.

Here we present the results of a study on the stability of Aquazol-based paints for use as a retouching paint alternative to Arabic gum-based paints. Aquazol 500 admixed with organic red pigments in different formulations was used to prepare artificially aged paint layers. The paint replicas were investigated by a multi-analytical approach based on analytical pyrolysis coupled with gas chromatography and mass spectrometry (Py-GC/MS), and thermogravimetry (TG), complemented by FTIR and LIBS spectroscopy.

To the best of our knowledge, this is the first ageing study of Aquazol 500 using analytical pyrolysis and thermogravimetric analysis. These techniques have been successfully used to investigate synthetic polymers in paint samples at a molecular level [24], [25], [26], [27], [28]. They yield information on the thermal stability of the binder and the formation of cross-linking bonds within the polymer during ageing [29], [30], [31], [32], [33]. They also highlight the presence of pigment/binder interactions [34] and the formation of pyrolytic products related to degradation [35], [36], [37], [38], [39].

Two different recipes for Aquazol-based retouching paint were prepared and the raw materials and paint replicas were analyzed before and after artificial ageing in Solarbox, in order to assess their stability over time. Paint layers were prepared with three commercial organic pigments, namely Irgazin red (diketo-pyrrolo-pyrrole, DPP), Alizarin (synthetic anthraquinone-based pigment lake), and Quindo pink (quinacridone), in order to investigate the influence of the pigments on the thermal features of the material during curing and ageing. An analysis of the pure materials used to prepare the paints was performed beforehand.

The influence of the pigments' components on the pyrolysis behavior of Aquazol was also investigated.

\section{Materials and methods}




\subsection{Paint samples and artificial ageing}

Eight paint layers with two different recipes for the binding medium and three different organic pigments (DPP, alizarin and quinacridone) were prepared on glass slides using Aquazol 500 as a binder. The set also included layers of the binder without pigments. Proportions and amounts of materials used for each paint preparation were chosen according to the instructions provided by Professor Richard Wolbers [40].

The materials for the paint preparations were: Aquazol 500 (Nr. 63905 Kremer Pigmente), diketopyrrolo-pyrrole (DPP, “Irgazine Ruby DPP-TR”, Nr. 23182 Kremer Pigmente, CI PR264), Alizarin (“Alizarine Crimson Dark”, Nr. 3610 Kremer Pigmente, CI PR83), Quinacridone (“Quindo Pink D”, Nr.23402 Kremer Pigmente, CI PV19), xanthan gum (La Saponaria, Pesaro, Italy, used in recipe A), glycerol (86\%, Nr.64900 Kremer Pigmente, used in recipe A), 2-phenoxyethanol (99\%, Nr. 77699 Sigma-Aldrich).

The choice of the binder/pigment ratio was based on CPVC (Critical Pigment Volume Concentration) parameters indicating the optimal concentration of pigment to add to the binder, on the basis of the physical and morphological features of the pigment powder particles: large pigment particles need less binder than the smaller ones [41].

DPP and alizarin, which have a similar particle size, were prepared in paints with a 1:4 ratio of pigment and fluid binder (33\% w/w aqueous Aquazol solution). Quinacridone, which has a smaller particle size, was prepared in paint with $15 \%$ in weight of pigment and $85 \%$ of fluid binder $(40 \%$ aqueous Aquazol solution).

Recipe A consisted of Aquazol 500 (binder), phenoxyethanol (preservative, 2-4 drops), pigment, xanthan gum and glycerol (1-2 drops), while recipe B consisted in Aquazol 500, phenoxyethanol and pigment only.

The paint layers were investigated before and after $777 \mathrm{~h}$ of artificial ageing in a Solar Box 3000E model (CO.FO.ME.GRA., Milan, $20 \times 42 \mathrm{~cm}$ ) equipped with a single Xenon lamp (2500 W) air cooled, prepared with a glass inner filter in soda-lime at $280 \mathrm{~nm}+$ IR. Inside the box the irradiance was uniform and perpendicular to the sample surface, with a constant irradiance of $500 \mathrm{~W} / \mathrm{m} 2$. During the ageing protocol, the maximum temperature reached by the black body temperature probe, placed next to the samples, was $45^{\circ} \mathrm{C}$. 
132 Samples were analyzed using a multi-shot pyrolyzer PY-3030D (Frontier Lab) coupled with a GC/MS 133 system composed of a $6890 \mathrm{~N}$ gas chromatograph combined with a 5973 mass selective single 134 quadrupole mass spectrometer (Agilent Technologies). The samples ( $\sim 0.2 \mathrm{mg}$ each) were inserted in 135 platinum sample cups. The cups were placed on top of the pyrolyzer at ambient temperature and then 136 moved into the furnace. Pyrolysis conditions were optimized as follows: pyrolysis chamber temperature $700{ }^{\circ} \mathrm{C}$, interface Py-GC $300{ }^{\circ} \mathrm{C}$. The GC injection port operated in split mode with a split ratio of 1:30. The chromatographic separation of pyrolysis products was performed with a fused silica capillary column HP-5MS (J\&W Agilent Technologies, 5\% diphenyl-95\% dimethylpolysiloxane, $30 \mathrm{~m} \times 0.25 \mathrm{~mm}$ i.d., $0.25 \mu \mathrm{m}$ film thickness), preceded by $2 \mathrm{~m}$ of deactivated fused silica pre-column with an internal diameter of $0.32 \mathrm{~mm}$. Chromatographic conditions were as follows: $40{ }^{\circ} \mathrm{C}$ for $5 \mathrm{~min}, 10{ }^{\circ} \mathrm{C} / \mathrm{min}$ up to $310^{\circ} \mathrm{C}, 20 \mathrm{~min}$ isothermal. Helium gas flow was set in constant flow mode at $1.2 \mathrm{~mL} / \mathrm{min}$ (purity 99.9995\%). MS parameters were: electron ionization (EI, $70 \mathrm{eV}$ ) in positive mode; ion source temperature $230{ }^{\circ} \mathrm{C}$; scan range $50-700 \mathrm{~m} / \mathrm{z}$; interface temperature $280{ }^{\circ} \mathrm{C}$. Per-fluorotributylamine (PFTBA) was used to tune the mass spectrometer. MSD ChemStation (Agilent Technologies) software was used for the data analysis, and peak assignment was based on a comparison with mass spectra libraries (NIST 2.0, WILEY275), mass spectra reported in the literature, and mass spectra interpretation.

\subsection{Attenuated total reflectance-Fourier Transform-Infrared spectrometer (ATR-FT-IR)} Infrared spectra were recorded using a FT-IR Agilent Technologies Spectrometer Cary 640, equipped with a universal attenuated total reflectance accessory (ATRU). A Few micrograms of powdered samples were analyzed with the following spectrometer parameters; resolution: $4 \mathrm{~cm}^{-1}$, spectral range: $500-4000 \mathrm{~cm}^{-1}$, number of scans: 16 . Spectrum software was used to process FTIR spectra.

\subsection{TGA}

A TA Instruments Thermobalance model Q5000 was used. TG measurements on $\sim 1 \mathrm{mg}$ of each sample were performed at $10{ }^{\circ} \mathrm{C} / \mathrm{min}$ scan rate, from $30{ }^{\circ} \mathrm{C}$ to $800{ }^{\circ} \mathrm{C}$ under $\mathrm{N}_{2}$ flow $(25 \mathrm{~mL} / \mathrm{min})$.

\subsection{LIBS}

LIBS analyses were performed with a double pulse technique, using a Nd:YAG laser operating on fundamental wavelength $(1064 \mathrm{~nm})$. The inter-pulse delay between the two pulses was $1 \mu \mathrm{s}$, while each laser pulse width was $15 \mathrm{~ns}$. The energy released was about $60 \mathrm{~mJ}$. The plasma signal was collected using the double reticulum spectrometer Avantes (Stellarnet. Inc), in the range 200-900 nm with an acquisition gate of $2.48 \mathrm{~ms}$ with a $2 \mu$ s delay with respect to the first laser shot. 


\subsection{PCA Analysis}

168 Principal component analysis of the data (PCA) of the covariance matrix was performed with the software Xlstat10.0 (Addinsoft, France).

\section{Results and discussion}

$172 \quad 3.1$ Characterization of the pure materials

$173 \quad 3.1 .1$ Aquazol 500 and additives

174 The TG curve of pure solid Aquazol 500, shown in Fig. 1A, shows a mass loss of about 5.9\% in the temperature range $30-130{ }^{\circ} \mathrm{C}$, typical of adsorbed water. At $434{ }^{\circ} \mathrm{C}$ (maximum of DTG curve) the polymer exhibits a main degradation step corresponding to a mass loss of about $93.5 \%$, with a residue at $800{ }^{\circ} \mathrm{C}$ of about $0.6 \%$. By rescaling the curve, excluding the water loss, the main degradation step corresponds to a $99.4 \%$ weight loss, indicating that the thermal degradation of Aquazol 500 occurs in a single step and that the pyrolytic process leads to volatile substances. Fig. $1 \mathrm{~B}$ and $\mathrm{C}$ shows the results obtained with films made from the Aquazol-based binder prepared according to recipes A and $\mathrm{B}$ without pigments. The two profiles are very similar, and in both cases, when the water contribution is subtracted, a single degradation step is observed at $414{ }^{\circ} \mathrm{C}$ and $423{ }^{\circ} \mathrm{C}$ for recipes A and B, respectively. These values are slightly lower than those observed for the degradation of pure Aquazol analyzed in bulk, and correspond to a $99+\%$ mass loss. No significant changes were observed when the TG experiments were performed on the corresponding artificially aged samples (Fig. 1D). These observations point out that reticulation and crosslinking phenomena do not occur during artificial ageing, and support the possibility of a good reversibility of Aquazol retouchings. Further solubilization experiments and cleaning tests are needed to better investigate the degree of reversibility of Aquazol paint applications.

Although glycerin and Xanthane gum are present in the recipe A formulation in a very low content, the thermal degradation of these two additives was also taken into account. Concerning glycerin, its TG curve in N2, reported in the literature [42], exhibits a single narrow degradation step in the range $177-231{ }^{\circ} \mathrm{C}$ with a maximum in the derivative curve at $211^{\circ} \mathrm{C}$, thus corresponding to a $98 \%$ mass loss. The TG curve of Xanthane gum was acquired and shows, at quite low temperatures $\left(50{ }^{\circ} \mathrm{C}\right)$, the evolution of absorbed water (corresponding to a mass loss of about $13.7 \%$ ) followed by the main degradation step ( $48.5 \%$ of mass loss in the temperature range $200-400{ }^{\circ} \mathrm{C}$ ). At $400{ }^{\circ} \mathrm{C}, 47.8 \%$ of sample mass is still present after which the degradation proceeds smoothly. At $900{ }^{\circ} \mathrm{C}$, a residue of about $26.5 \%$ in mass is found. As expected considering their low amount in the recipes, the degradation of glycerin and Xanthane was not detected in the TG curves of the Aquazol recipe A paint layers. 
The thermal degradation of the samples was investigated at a molecular level by GC/MS analysis of the pyrolysis products, providing additional information on the pyrolytic behavior. The pyrolytic degradation of Aquazol 500 is reported in [13], and is characterized by an initial chain scission by cleavage of the $\mathrm{C}-\mathrm{N}$ bond followed by two degradation pathways: one involving the cleavage of another of the $\mathrm{C}-\mathrm{N}$ bonds followed by a cyclization reaction producing ethyl-oxazoline, and the other involving the cleavage of the $\mathrm{C}-\mathrm{C}$ bond next to the nitrogen atom $(\alpha \beta)$ followed by a McLafferty rearrangement reaction.

Fig. 2A shows the pyrogram obtained in the Py-GC/MS analysis of a sample from the film of the Aquazol binder prepared according to recipe B, without any pigment. Four clusters of thermal degradation products produced in the flash pyrolysis at $700{ }^{\circ} \mathrm{C}$ can be identified at different retention times [13], and the list of the identified pyrolysis products is reported in Table 1. The first cluster of signals (1-4 min) is characterized by low molecular weight molecules, including isocyanates, nitriles, amines, alkenes and ketones (LMW). The second cluster (7-14 min) is more heterogeneous and, at this range of retention times, propionamide ( $\mathrm{P}$ in the table) with related alkylated structures, and monomers (M) and sesquimers with related alkylated structures are eluted. In this region, the most abundant peaks correspond to the sesquimers. The dimers (D), with the related alkylated structures, are eluted in retention time range of between 14 and $18 \mathrm{~min}$. The last cluster, between 18 and $20 \mathrm{~min}$, features the presence of trimers (T) and of the related alkylated structures. Fig. 2B reports the PyGC/MS chromatographic profile of the Aquazol 500 paint layer (recipe B without pigment) after the artificially ageing treatment. No significant changes in the pyrolytic profile of the polymer or in the mass spectra of the pyrolysis products are observed after ageing. No peak corresponding to new compounds is observed, and the relative abundance of the various classes of compounds produced during pyrolysis (low molecular weight molecules, monomers, sesquimers, dimers and trimers) remain almost unchanged in the artificially aged material, compared to the unaged material. The PyGC/MS profiles observed before and after artificial ageing show no significant changes for the investigated Aquazol paint layers prepared according to both recipes $\mathrm{A}$ and $\mathrm{B}$. The different pigments do not induce a variation of the pyrolysis behavior after photoageing.

\subsubsection{Pigments}

The thermal behavior of the commercial pigments was also investigated through TG.

The irgazine ruby pigment (PR264) belongs to the diketo-pyrrolo-pyrrole (DPP) dye family with two biphenyl substituents in positions 3,6. Its TG curve (Fig. 3A) is relatively simple, only showing a single step mass loss at $514{ }^{\circ} \mathrm{C}$ corresponding to about $84 \%$ in weight. However, the residue at 900 
${ }^{\circ} \mathrm{C}$ is about $16 \%$ in weight, indicating that an inorganic matrix is also present, probably introduced in the formulation as a filler or complexing agent. This matches the results of LIBS analysis of DPP where typical spectral lines of calcium, aluminum and magnesium are present. Alizarin is a derivative of anthraquinone with two hydroxyl substituents in position 1,2. Alizarin based pigments, such as Garanza lake (PR83), are obtained by the precipitation of its aluminum complex, usually in the form of hydrated aluminate or hydrated silicoaluminate of calcium and/or magnesium. The TG curve of Kremer's alizarin shows a complex profile due to the mixture of kaolinite and alizarin dye (Fig. 4A): a residue percentage of $43 \%$ at $900{ }^{\circ} \mathrm{C}$ is observed, attributed to the inorganic component. This is consistent with the IR spectrum of the alizarin pigment (Supplementary data, Fig. S1), which corresponds to the overlap of the spectra of pure alizarin and of hydrated silicoaluminate associated with mineral kaolinite [43]. The LIBS spectra of Alizarin lake (Supplementary data, Fig. S2) shows the typical lines of silicon, calcium, magnesium, aluminum (probably ascribed to the presence of kaolinite): it also highlights the typical lines of titanium, revealing that a titanium-based filler is also present.

A marked dehydration is observed in the $\mathrm{TG}$ in the range $\mathrm{T}_{\mathrm{amb}}-135{ }^{\circ} \mathrm{C}$, with two distinct and reproducible DTG maxima at $71^{\circ}$ and $133{ }^{\circ} \mathrm{C}$. These can be assigned to the release of adsorbed water (at $75^{\circ} \mathrm{C}$ ) and of crystallization water in the kaolinite pores (at $132{ }^{\circ} \mathrm{C}$ ) [44], corresponding to an overall mass loss of about 13\%. Increasing the temperature, the degradation pattern of alizarin lake shows a weak mass loss around $312^{\circ} \mathrm{C}$, followed by the main mass loss occurring at $487^{\circ} \mathrm{C}$, preceded by a shoulder at $429{ }^{\circ} \mathrm{C}$. The overall mass loss amounts to about $45 \%$. Over $550{ }^{\circ} \mathrm{C}$, the mass loss continues smoothly and the residue at $900{ }^{\circ} \mathrm{C}$ is about $43.1 \%$, which is consistent with the organic and inorganic composition of the pigment. The subsequent mass losses at $200-700{ }^{\circ} \mathrm{C}$ are attributed to the degradation of alizarin dye and to the reorganization in the octahedral layer of kaolinite. In the temperature range $450-650{ }^{\circ} \mathrm{C}$, the dehydroxylation of kaolinite and formation of metakaolinite takes place, in line with the literature.

Among the pigments considered within this work, only the quinacridone "Pink Quindo D" does not contain any inorganic component. Its TG curve (Fig. 5A) shows a sharp single degradation step at $554{ }^{\circ} \mathrm{C}$ corresponding to a $97+\%$ mass loss. The ATR-FTIR spectrum of this pigment (Supplementary data, Fig. S3) matches that of pure Quinacridone from Wiley Subscription Services, Inc. (US), thus confirming that no inorganic complexing agent or additive has been employed to produce this pigment. 
3.2 Characterization of the paint layers based on Aquazol 500 and pigments

267 The TG analyses of the paint replicas obtained according to both recipes A and B show very interesting features.

The TG curves of the Aquazol 500 paint layers containing DPP (Fig. 3B and C) exhibit a single degradation step at $404^{\circ} \mathrm{C}$ (recipe A) and at $407^{\circ} \mathrm{C}$ (recipe B), corresponding to a mass loss of about $87 \%$. The residue observed at $800{ }^{\circ} \mathrm{C}$ is about $11 \%$, in agreement with the $1: 1 \mathrm{DPP} /$ Aquazol mass ratio. TG experiments on the same paint layers after artificial ageing (Fig. 3D) do not show any significant difference compared to the unaged ones. The results indicate that a strong interaction between the pigment DPP and the polymer takes place. In fact, their thermal decomposition occurs in a single step at a temperature lower than those of both polymer and pigment alone. This might indicate the formation of a less stable structure, due to the interactions between the amide bonds in the pigment and in the polymer, leading to an alteration of the quaternary structure of the polymer. The Py-GC/MS analysis of the recipes containing DPP showed the presence of specific pyrolysis peaks corresponding to the thermal degradation of the organic dye. From a qualitative point of view, the pyrolysis profile of Aquazol mixed with DPP is the same as pure Aquazol added with the specific pyrolysis products of DPP. However, differences in the relative abundances of pyrolysis products were observed, namely a relatively higher abundance of dimer and trimers relative to propionamide and low molecular weight products. This might be related to the interactions between the pigment and the polymer. The differences were also highlighted by the principal component analysis of the pyrolysis semi-quantitative data presented in Section 3.3. No significant alteration in the pyrolysis profile was observed after artificial ageing, in line with the results presented for the TG analysis. Aquazol 500 paint layers containing alizarin exhibit a more complex TG curve shape (Fig. 4B and C). In the temperature range below $200^{\circ} \mathrm{C}$, where the loss of water occurs, there are the typical signal of alizarin- and kaolinite based-pigments with two weak maxima in the derivative curve. The main degradation step occurs in the range from 384 to $394{ }^{\circ} \mathrm{C}$, depending on the recipe used and the ageing of the sample, corresponding to about a $45 \%$ mass loss (50\% compared to the dehydrated sample). Thus, in the paint layers containing the alizarin pigment, the main thermal degradation occurs at a lower temperature than in the pure Aquazol layer. In addition, in the derivative curve it is apparent that the peak related to the main weight loss is wider with respect to the pure binder. These data combined suggest that a partial depolymerization has occurred with respect to the unpigmented layer. At higher temperatures (temperature range $450-700^{\circ} \mathrm{C}$ ), the TG curves also show a broad mass loss corresponding to about $22-23 \%$ (about $25 \%$ if the water loss is not considered) occurring in a wide temperature range depending on the recipe used for the formulation. This second mass loss is most probably due to the degradation of stable compounds, formed because of the 
interaction between the pigment and Aquazol, and possibly characterized by a higher molecular weight than the main fraction. The extent of the interaction depends on the recipe used to produce the paint, and in both cases the residue at $800{ }^{\circ} \mathrm{C}$ is about $25 \%$ compared to the dehydrated sample. Both the depolymerization of the binder and the formation of the stable compounds, possibly characterized by a higher molecular weight compared to the unmodified Aquazol, are more pronounced after artificial ageing (Fig. 4D). The main thermal degradation occurs at $384{ }^{\circ} \mathrm{C}$ for recipe $\mathrm{A}\left(10^{\circ} \mathrm{C}\right.$ lower than in the unaged layer), while the more stable compounds start to degrade at around $450{ }^{\circ} \mathrm{C}$ and are not completely degraded at $800{ }^{\circ} \mathrm{C}$. The particular reactivity of Aquazol with alizarin lake might be explained by the presence of kaolinite and metakaolinite, which are known for their catalytic properties [45], [46], [47], [48]. For example, a study reported their use in catalysis, after thermalactivation, in transesterification to produce biodiesel using frying oil [49]. These minerals are also known for their use in the catalytic cracking reactions of alkanes and alkenes [49], [50]. Kissin proposed the solid acidic catalysis of kaolinite in these reactions [50].

The pyrograms of the paint layers containing Alizarin, both before and after artificial ageing, present significant differences in the relative abundance of pyrolysis products compared to the pyrolysis profile of pure Aquazol and of Aquazol paint containing the other two pigments investigated. The relative amounts of the peaks corresponding to the monomers is higher than in the pyrograms of all the other aquazol paint layers which do not contain alizarin, as shown in Fig. 2C. The relative abundance of the monomer (peak number 10) is in this case higher than all the other pyrolysis products, resulting in a very specific chromatographic profile. The high amounts of the monomer in the pyrogram is consistent with the depolymerization observed by TG. The contribution of the fraction characterized by a higher molecular weight than Aquazol is predictably not visible in the pyrograms, probably due to their higher thermal stability revealed in the TG experiments.

The Aquazol 500 paint layers containing Quinacridone (Fig. 5B and C) show TG profiles where the main weight loss, due to Aquazol, occurs at very similar temperatures to those of the unpigmented paint layers, corresponding to a mass loss of about $66 \%$ at $410{ }^{\circ} \mathrm{C}$ (recipe A) and $432{ }^{\circ} \mathrm{C}$ (recipe B). This mass loss exactly matches the composition of the paint layer (Aquazol/pigment 2:1). The secondary mass loss, probably related to the degradation of the pigment, varies from $25 \%$ (recipe A) to $29 \%$ (recipe B), with a residue at $800{ }^{\circ} \mathrm{C}$ as high as $4.5 \%$ and $3.6 \%$, respectively. In addition, the secondary degradation spans from $440{ }^{\circ} \mathrm{C}$ to $530{ }^{\circ} \mathrm{C}$ in the case of the paint formula prepared according to recipe A (with a single maximum in the derivative curve at $494^{\circ} \mathrm{C}$ ), while in the sample prepared according to recipe $\mathrm{B}$, the mass loss is much broader $\left(460-660{ }^{\circ} \mathrm{C}\right.$ with two maxima at 567 ${ }^{\circ} \mathrm{C}$ and $620^{\circ} \mathrm{C}$ in the DTG curve). 
333 The two different formulations seem to produce opposite effects: the presence of glycerin and 334 Xanthan gum (recipe A) lowers the Quinacridone decomposition temperature by about $60{ }^{\circ} \mathrm{C}$. On the 335 other hand, in the formulation without additives (recipe B) the thermogravimetric profile suggests that beside the unaltered pigment (mass loss occurring at $567{ }^{\circ} \mathrm{C}$, very close to that of the pure pigment), there are other compounds with a higher thermal stability within the paint layer, possibly due to the aggregation of aquazol and/or the pigment during drying [50].

339 The Py-GC/MS analysis of the paint layers containing Quinacridone shows the presence of the specific pyrolysis products derived from the pigment, although in very low amounts compared to the peaks due to the binder. The pyrolysis profile of the paint layer after artificial ageing did not show any significant difference in composition compared to the corresponding unaged sample. Since the pyrolysis profile of the binder is not significantly altered by the presence of the quinacridone pigment, it is possible that the aggregates highlighted in recipe B are due to the auto-aggregation of the pigment, inhibited by xanthan gum and glycerin in recipe A.

346 The strongest differences between the freshly prepared and the aged samples were highlighted by 347 FTIR analysis. The recipe B paint layer without pigment, both recipe A and B paint layers containing alizarin, and recipe $\mathrm{B}$ paint containing quinacridone showed the appearance of new bands as a consequence of ageing. Fig. 6 shows the FT-IR spectrum of the Aquazol 500 paint layer recipe B without pigment, before and after artificial ageing. In the spectra of the aged material, a band appears at $1734 \mathrm{~cm}-1$, and in addition the absorption band at $3267 \mathrm{~cm}-1$ has increased in intensity while the band at $3480 \mathrm{~cm}^{-1}$ has decreased compared to the unaged material. The bands at $1734 \mathrm{~cm}-1$ and at $3267 \mathrm{~cm}^{-1}$ are characteristic of the hydroxyl group stretching and carbonyl group stretching of carboxylic acids, respectively [23] (Table 2). The formation of carboxylic acids indicates that a certain degree of photo-oxidation of Aquazol 500 has occurred during ageing. The low intensity of the $1734 \mathrm{~cm}-1$ band indicates that only a small fraction of the polymer was involved in the oxidation reactions, which was insufficient to produce significant variations in the pyrolysis profiles.

\subsection{Principal component analysis (PCA)}

360 Due to the high number of pyrolysis products highlighted in the chromatograms, the Py-GC/MS data were interpreted using Automated Mass Spectral Deconvolution and Identification System (AMDIS), a free software application available from NIST. This software operates the deconvolution of the overlapping peaks based on their mass spectra. A dedicated library of mass spectra of the pyrolysis products of Aquazol was created and used to collect the data relative to the peak area of each compound. For the PCA analysis, the relative abundances of the five classes of the thermal degradation products of Aquazol were used, namely low molecular weight molecules (LMW), 
propionamide and related alkylated structures $(\mathrm{P})$, monomer and related alkylated structures $(\mathrm{M})$, dimer and related alkylated structures (D), trimer and related alkylated structures (T). Theses relative abundances were calculated as the sum of the integration results of the thermal degradation products of each class, expressed as a percentage of the total area. The assignment of each pyrolysis product

371 to its class is indicated in Table 1.

372 A multivariate analysis of the data obtained together with the decomposition temperature of Aquazol 373500 determined by TG experiments was performed by principal component analysis (PCA) of the 374 covariance matrix.

375 The scatter plot shows that the samples of the paint layers containing alizarin (both recipes A and B, 376 before and after ageing) are placed at negative values of PC1 and at high values of PC2, in a different 377 region of the scatterplot compared to those of all the other paint layers. The paint samples containing 378 Aquazol without any pigment and those containing quinacridone are located in the same region as 379 the scatter plot, at positive PC1 values, which is consistent with the lack of influence of quinacridone 380 on the behavior of the polymer. The samples containing DPP form a separate compact group at 381 negative values of both PC1 and PC2, characterized by a high trimeric structure content in the 382 pyrogram.

383 The most notable differences in the pyrolysis profiles were highlighted by the PCA analysis in the 384 samples containing alizarin. An examination of the loading plot suggests that the relatively higher 385 values of the relative abundance of monomers and of the related alkylated structures is the main 386 feature of the pyrolysis profile, which differentiates the samples containing alizarin from the other 387 samples. We hypothesized that this different behavior could be due to depolymerization reactions, 388 possibly catalyzed by the inorganic fraction of the alizarin pigment.

389 As expected, depolymerization and intermolecular interactions between the polymer and the 390 pigments, responsible for the differences in the thermal degradation highlighted by PCA, do not 391 produce differences in the IR spectra, since they do not entail significant changes in the functional 392 groups. However, FT-IR spectroscopy proves efficient in highlighting oxidation phenomena. 


\section{Conclusions}

The application of a multi-analytical approach based on the combination of thermoanalytical, mass spectrometric and spectroscopic techniques enabled us to assess the stability of Aquazol 500 as a paint binder during ageing as well as the occurrence of pigment-Aquazol 500 interactions, and their evolution during ageing.

The FT-IR analysis of paint layers prepared with Aquazol 500 without pigments highlighted the occurrence of oxidation reactions during artificial ageing, leading to the appearance of a band at 1734 $\mathrm{cm}-1$. Nevertheless, Py-GC/MS profiles of aged paint layers did not show significant variations when compared to the non-aged paint, indicating that only a small fraction of the polymer was oxidized, in agreement with the data reported in the literature [23]. This thus confirms its potential for use as a binder for retouching paints in the restoration of works of art.

When Aquazol 500 was used in formulations containing pigments, Aquazol -pigments interactions were observed. Depending on the pigment used, the following results were obtained:

- DPP-Aquazol 500 paint layers: a very strong DPP-Aquazol interaction was observed, leading to TG curves showing a single degradation step for DPP and Aquazol 500, at a temperature lower than those of pure DPP and Aquazol 500. No evidence was observed of a significant modification in the thermal behavior of the paint due to the presence of additives such as glycerol and xanthan gum (recipe A), or due to ageing. PCA analysis of Py-GC/MS data highlighted that the pyrolytic profile appears to be significantly different from a quantitative point of view from that of pure Aquazol, which may be related to the interaction of the polymeric chain and the pigment. The presence of amide bonds in both structures might account for their strong interaction.

- Alizarine lake-Aquazol 500 paint layers: a strong interaction was observed leading to a partial depolymerization of the binder highlighted in the TG curve and confirmed by the pyrogram obtained by analytical pyrolysis, with the predominant formation of the monomer. The data analysis using PCA also highlighted this behavior. In addition, stable compounds are formed when alizarin lake is present in the paint layer, probably due to the presence of kaolinite in the pigment formulation. The presence of additives and of artificial ageing played a minor role in the degradation pattern of these paints.

- Quinacridone-Aquazol 500 paint layers: the presence of Quinacridone did not influence the behavior of the polymer, as assessed both by TG and analytical pyrolysis. However, quinacridone behaves differently in the paint layers than as a pure pigment, mostly depending on the recipe used in the paint production, forming varyingly stable aggregates. 
425 The adopted analytical methods achieved complementary information: FT-IR spectroscopy allowed 426 us to observe the formation of oxidized functionalities even if in very low concentration, while 427 thermal analysis techniques achieved information on intermolecular interactions between the polymer 428 and the pigments.

429 Aquazol 500 is now being used to retouch paintings. This study highlights that the stability of the 430 polymer, as shown in a previous study limited to $\mathrm{TiO} 2$ nanoparticles [23], is affected by the presence 431 of pigments. This is particularly the case of organic lakes containing an inorganic fraction in the 432 formulation, leading to different physico-chemical phenomena, depending on the nature of the 433 pigment.

\section{Acknowledgments}

436 The authors acknowledge Prof. Roberto Franchi of the University of Urbino "Carlo Bo" (Department 437 of Pure and Applied Sciences DISPEA), Dr. Emanuela Grifoni of the Institute of Chemistry of 438 Organometallic Compounds, National Research Council (CNR) of Pisa (Applied and Laser 439 Spectroscopy Laboratory), Prof. Pier Paolo Lottici, Prof. Danilo Bersani and Prof. Claudio Oleari of 440 the University of Parma (Department of Mathematical, Physical and Computer Sciences), Dr. 441 Valentina Emanuela Selva Bonino and the restorer Roberto Bestetti of the Association CESMAR7 442 (Center for the Study of Materials for Restoration). We are also grateful to Prof. Maria Perla 443 Colombini and Dr. Emma Cantisani for having made the Solar Box available at the Institute for the 444 Conservation and Valorization of Cultural Heritage (ICVBC) of the National Research Council 445 (CNR) of Florence. A special thanks to Prof. Richard Wolbers of the University of Delaware USA 446 (Department of Art and Conservation), who provided essential guidance in starting the 447 experimentation, and contributed to important decisions regarding sample preparation. The authors 448 also acknowledge an anonymous reviewer for useful comments and suggestions. 


\section{References}

[1] T.A. Chamberlin, N.L. Madison, US Patent 4,001,160 (1997).

[2] Chemistry Polymer Innovation, Inc, Technical Sheet http://polymerchemistry.com (2010)

[3] S.C. Lee, Y. Chang, J.S. Yoon, C. Kim, I.C. Kwon, Y.H. Kim, S.Y. Jeong Synthesis and micellar characterization of amphiphilic diblock copolymers based on poly(2-ethyl-2oxazoline) and aliphatic polyesters Macromolecules, 32 (1999), pp. 1847-1852

[4] S. Zalipsky, C.B. Hansen, J.M. Oaks, T.M. Allen, S. Zalipsky, C.B. Hansen, J.M. Oaks, T.M. Allen Evaluation of blood clearance rates and biodistribution of poly(2-oxazoline)grafted liposomes J. Pharm. Sci., 85 (1996), pp. 133-137

[5] R.C. Wolbers, M. McGynn, D. Duerbeck, V. Dorge, C. Howlett Poly (2-Ethyl-2-Oxazoline): a new conservation consolidant V. Dorge, F. Carey Howlett (Eds.), Painted Wood: History and Conservation, The Getty Conservation Institute, Los Angeles (1998), pp. 514-527

[6] A. Krieg, C. Weber, R. Hoogenboom, C.R. Becer, U.S. Schubert Block copolymers of poly(2-oxazoline)s and poly(meth)acrylates: a crossover between cationic ring-opening polymerization (crop) and reversible addition-fragmentation chain transfer (raft) ACS Macro Lett., 1 (2012), pp. 776-779

[7] C.A. Metzger, C. Maines, J. Dunn Painting Conservation Catalog Volume III: Inpainting AIC, 1156 15th St. NW, Suite 320 Painting. Speciality. Group, Washington. D.C. (2011), p. 114

[8] B. Ebert, B. Singer, N. Grimaldi Aquazol as a consolidant for matte paint on Vietnamese paintings J. Inst. Conservation, 35 (2012), pp. 62-76

[9] J. Arslanoglu Aquazol as used in conservation practice WAAC Newsl., 26 (1) (2004)

[10] K. Lechuga Aquazol as a heat set adhesive for textile conservation treatments CA. Postprints The Textile Specialty Group Postprints 19 Contain the Proceedings from the Textile Sessions of AIC's 37th Annual Meeting in Los Angeles (2009), pp. 187-193

[11] S. Zanini, L. Zoia, E.C. Dell'Orto, A. Natalello, A.M. Villa, R. Della Pergola, C. Riccardi Pages 791-800, Plasma polymerized 2-ethyl-2-oxazoline: chemical characterization and study of the reactivity towards different chemical groups Mater. Des., 108 (2016), pp. $791-800$ 
[12] T.T. Chiu, B. Thill, W.J. Fairchock Poly(2-ethyl-2-oxazoline): a new water and organic soluble adhesive, Water Soluble Polymers J.E. Glass (Ed.), Advances in Chemistry Series 213, American Chemical Society, Washington D.C (1986), pp. 426-433

[13] S. Orsini, J. La Nasa, F. Modugno, M.P. Colombini Characterization of Aquazol polymers using techniques based on pyrolysis and mass spectrometry J. Anal. Appl. Pyrolysis, 104 (2013), pp. 218-225

[14] C.C. Magee The treatment of severely deteriorated enamel, ICOM 12th Triennial Meeting Lyon, 2 (1999), pp. 787-792

[15] J. Arslanoglu Evaluation of the use of Aquazol as an adhesive in painting conservation WAAC Newsl., 25 (2) (2003)

[16] D. De Luca, L. Borgioli, L. Sabatini, V. Viti Manufatti dipinti su supporto tessile. La reintegrazione delle lacune: proposta di materiali alternative Kermes, 88 (2012), pp. 4254

[17] F. Jordan Reverse painting on glass in the british galleries V\&A Conservation J., 39 (2001), p. 6

[18] S. Friend Technical Exchange, Aquazol: one conservator's empirical evaluations WAAC Newsl., 18 (2) (1996)

[19] D. De Luca, L. Borgioli, S. Orsini, S. Burattini Manufatti dipinti su supporto tessile. Proposte di materiali alternativi per la stuccatura delle lacune. Comportamento all'invecchiamento Kermes, 90 (2013), pp. 67-90

[20] S. Burattini, L. Baratin, L. Borgioli, L. Sabatini, S. Orsini, V. Viti, E. Falcieri, D. De Luca Scanning electron microscopy in monitoring the aging of alternative materials for plastering of canvas manufacture products Microscopie (2014), pp. 47-51

[21] C. Shelton The Use of Aquazol-based Gilding Preparations WAG Postprints, AIC Meeting Virginia, Norfolk (1996)

[22] C. De Courlon, S. Ives, P. Dredge Fields of colour: the conservation of matt, synthetic paintings by Michael Johnson AICCM, Bull. Aust. Inst. Conservation Cult. Material, 36 (2) (2015), pp. 136-146

[23] A. Colombo, F. Gherardi, S. Goidanich, J.K. Delaney, E.R. de la Rie, M.C. Ubaldi, L. Toniolo, R. Simonutti Highly transparent poly(2-ethyl-2-oxazoline)-TiO2 nanocomposite 
coatings for the conservation of matte painted artworks RSC Adv., 5 (2015), pp. 8487984888

[24] J. La Nasa, S. Orsini, I. Degano, A. Rava, F. Modugno, M.P. Colombini A chemical study of organic materials in three murals by Keith Haring: a comparison of painting techniques Microchem. J., 124 (2015), pp. 940-948

[25] J. La Nasa, I. Degano, F. Modugno, M.P. Colombini Alkyd paints in art: characterization using integrated mass spectrometry Anal. Chim. Acta, 797 (2013), pp. 64-80

[26] I. Bonaduce, M.P. Colombini, I. Degano, F. Di Girolamo, J. La Nasa, F. Modugno, S. Orsini Mass spectrometric techniques for characterizing low-molecular-weight resins used as paint varnishes Anal. Bioanal. Chem., 405 (2013), pp. 1047-1065

[27] M.P. Colombini, A. Andreotti, I. Bonaduce, F. Modugno, Erika Ribechini Analytical strategies for characterizing organic paint media using gas chromatography/mass spectrometry Acc. Chem. Res., 43 (2010), pp. 715-727

[28] K.L. Sobeih, M. Baron, J. Gonzalez-Rodriguez Recent trends and developments in pyrolysis-gas chromatography J. Chromatogr. A, 1186 (2008), pp. 51-66

[29] N. Dadvand, R.S. Lehrle, I.W. Parsons, M. Rollinson, I.M. Horn, A.R. Skinner Use of pyrolysis-GC-MS to assess the thermal degradation behaviour of polymers containing chlorine II. Thermal stability characteristics of Neoprene/chlorobutyl rubber composites, before and after artificial ageing Polym. Degrad. Stab., 67 (2000), pp. 407-419

[30] A. Lattuati-Derieux, S. Thao-Heu, B. Lavédrine Assessment of the degradation of polyurethane foams after artificial and natural ageing by using pyrolysis-gas chromatography/mass spectrometry and headspace-solid phase microextraction-gas chromatography/mass spectrometry J. Chromatogr. A, 1218 (2011), pp. 4498-4508

[31] Z. Doležal, V. Pacáková, J. Kovářová The effects of controlled aging and blending of lowand high-density polyethylenes, polypropylene and polystyrene on their thermal degradation studied by pyrolysis gas chromatography J. Anal. Appl. Pyrolysis, 57 (2001), pp. 177-185

[32] R. Yang, J. Zhao, Y. Liu Oxidative degradation products analysis of polymer materials by pyrolysis gas chromatography-mass spectrometry Polym. Degrad. Stab., 98 (2013), pp. 2466-2472 
[33] S. Weia, V. Pintusa, M. Schreiner Photochemical degradation study of polyvinyl acetate paints used in artworks by Py-GC/MS J. Anal. Appl. Pyrolysis, 97 (2012), pp. 158-163

[34] V. Pintus, S. Wei, M. Schreiner Accelerated UV ageing studies of acrylic, alkyd, and polyvinyl acetate paints: influence of inorganic pigments Microchem. J., 124 (2016), pp. 949-961

[35] D. Tamburini, D. Sardi, A. Spepi, C. Duce, M.R. Tinè, M.P. Colombini, I. Bonaduce An investigation into the curing of urushi and tung oil films by thermoanalytical and mass spectrometric techniques Polym. Degrad. Stab., 134 (2016), pp. 251-264

[36] L. Ghezzi, C. Duce, L. Bernazzani, E. Bramanti, M.P. Colombini, M.R. Tiné, Ilaria Bonaduce Interactions between inorganic pigments and rabbit skin glue in reference paint reconstructions J. Therm. Analysis Calorimetr, 122 (2015), pp. 315-322

[37] C. Duce, L. Ghezzi, M. Onor, I. Bonaduce, M.P. Colombini, M.R. Tiné, E. Bramanti Physico-chemical characterization of protein-pigment interactions in tempera paint reconstructions: casein/cinnabar and albumin/cinnabar Anal. Bioanal. Chem., 402 (2012), pp. 2183-2193

[38] I. Bonaduce, L. Carlyle, M.P. Colombini, C. Duce, C. Ferrari, E. Ribechini, P. Selleri, M.R. Tiné New insights into the ageing of linseed oil paint binder: a qualitative and quantitative analytical study PLoS One, 7 (11) (2012), p. e49333, 10.1371/journal.pone.0049333

[39] C. Duce, E. Bramanti, L. Ghezzi, L. Bernazzani, I. Bonaduce, M.P. Colombini, A. Spepi, S. Biagi, M.R. Tiné Interactions between inorganic pigments and proteinaceous binders in reference paint reconstructions Dalton Transation, 42 (2013), p. 5975

[40] R. Wolbers Giornata di Studio e Workshop sull'utilizzo dell'Aquazol 4-5-6 giugno La Venaria Reale, Torino (2014)

[41] W.K. Asbeck, M. Van Loo Critical pigment Volume relationship, industrial \& engineering Chemistry ACS Publ., 41 (1949), pp. 1470-1475

[42] A.Y. Maturana Cordoba, J.D. Pagliuso Thermal decomposition behavior of crude glycerin 21st Brazilian Congress of Mechanical Engineering by ABCM October 24-28 (2011) Natal, RN, Brazil 
[43] V. Della Porta, E. Bramanti, B. Campanella, M.R. Tiné, Celia Duce Conformational analysis of bovine serum albumin adsorbed on halloysite nanotubes and kaolinite: a Fourier transform infrared spectroscopy study RSC Adv., 6 (2016), pp. 72386-72398

[44] P.A. Alaba, Y.M. Saniab, W.M.A. Wan Daud Kaolinite properties and advances for solid acid and basic catalyst synthesis RSC Adv., 5 (2015), pp. 101127-101147

[45] F. Moodi, A.A. Ramezanianpour, A.S. Safavizadeh Evaluation of the optimal process of thermal activation of kaolins Sci. Iran. A, 18 (4) (2011), pp. 906-912

[46] J. Ramírez-Ortiz, J. Medina-Valtierra, M. Martínez Rosales Used frying oil for biodiesel production over kaolinite as catalyst Int. J. Chem. Mol. Nucl. Mater. Metallurgical Eng., 5 (8) (2011), pp. 696-699

[47] T.-J. Ronga, J.-k. Xiaob The catalytic cracking activity of the kaolin-group minerals Mater. Lett., 57 (2002), pp. 297-301

[48] Y.V. Kissin Chemical mechanism of hydrocarbon cracking over solid acidic catalysts J. Catal., 163 (1996), pp. 50-62

[49] J. Ramírez-Ortiz, J. Medina-Valtierra, M. Martínez Rosales Used frying oil for biodiesel production over kaolinite as catalyst Int. J. Chem. Mol. Nucl. Mater. Metallurgical Eng., 5 (8) (2011), pp. 696-699

[50] U. Keller, K. Müllen, S. De Feyter, F.C. De Schryver Hydrogen-bonding and phaseforming behavior of a soluble quinacridone Adv. Mater., 8 (1996), pp. 490-493 


\section{Figure Captions}

Fig. 1. TG curves of: a) Aquazol 500 in bulk; b) paint layer of Aquazol 500, recipe A, without pigment; c) paint layer of Aquazol 500, recipe B, without pigment; d) paint layer of Aquazol 500, recipe $\mathrm{A}$, without pigment, after artificial ageing.

Fig. 2. Chromatograms obtained in the GC/MS analysis of: a) paint layer of Aquazol 500, recipe B, without pigment; b) paint layer of Aquazol 500, recipe B, without pigment, after artificial ageing; c) paint layer of Aquazol 500, recipe B, with alizarin.

Fig. 3. Structural formula of diketo-pyrrolo-pyrrole and TG curves of: a) diketo-pyrrolo-pyrrole (DPP) pigment powder; b) paint layer of Aquazol 500, recipe A, containing DPP; c) paint layer of Aquazol 500, recipe B, containing DPP; d) paint layer of Aquazol 500, recipe A, containing DPP, after artificial ageing.

Fig. 4. Structural formula of alizarin andTG curves of: a) alizarin pigment powder; b) paint layer of Aquazol 500, recipe A, containing alizarin; c) paint layer of Aquazol 500, recipe B, containing alizarin; d) paint layer of Aquazol 500, recipe A, containing alizarin, after artificial ageing.

Fig. 5. Structural formula of quinacridone and TG curves of: a) Quinacridone pigment powder; b) paint layer of Aquazol 500, recipe A, containing Quinacridone; c) paint layer of Aquazol 500, recipe B, containing Quinacridone.

Fig. 6. ATR-FT-IR of Aquazol 500 paint layer, recipe B, without pigment: A) before artificial ageing and B) after artificial ageing. Peak assignation is shown in Table 2.

Fig. 7. PCA loading plot and scatter plot of the Py-GC/MS data (abundance of low molecular weight molecules: LMW; propionamide and related alkylated structures: P; monomer and related alkylated structures: M; dimer and related alkylated structures: D; trimer and related alkylated structures: T) and TG data (temperature of decomposition of the polymer) of the aged and unaged samples, recipes A and B, without and with the organic pigments diketo-pyrrolo-pyrrole (DPP), quinacridone (QUI) and alizarin (ALI). 
$621 \quad$ Fig 1

622
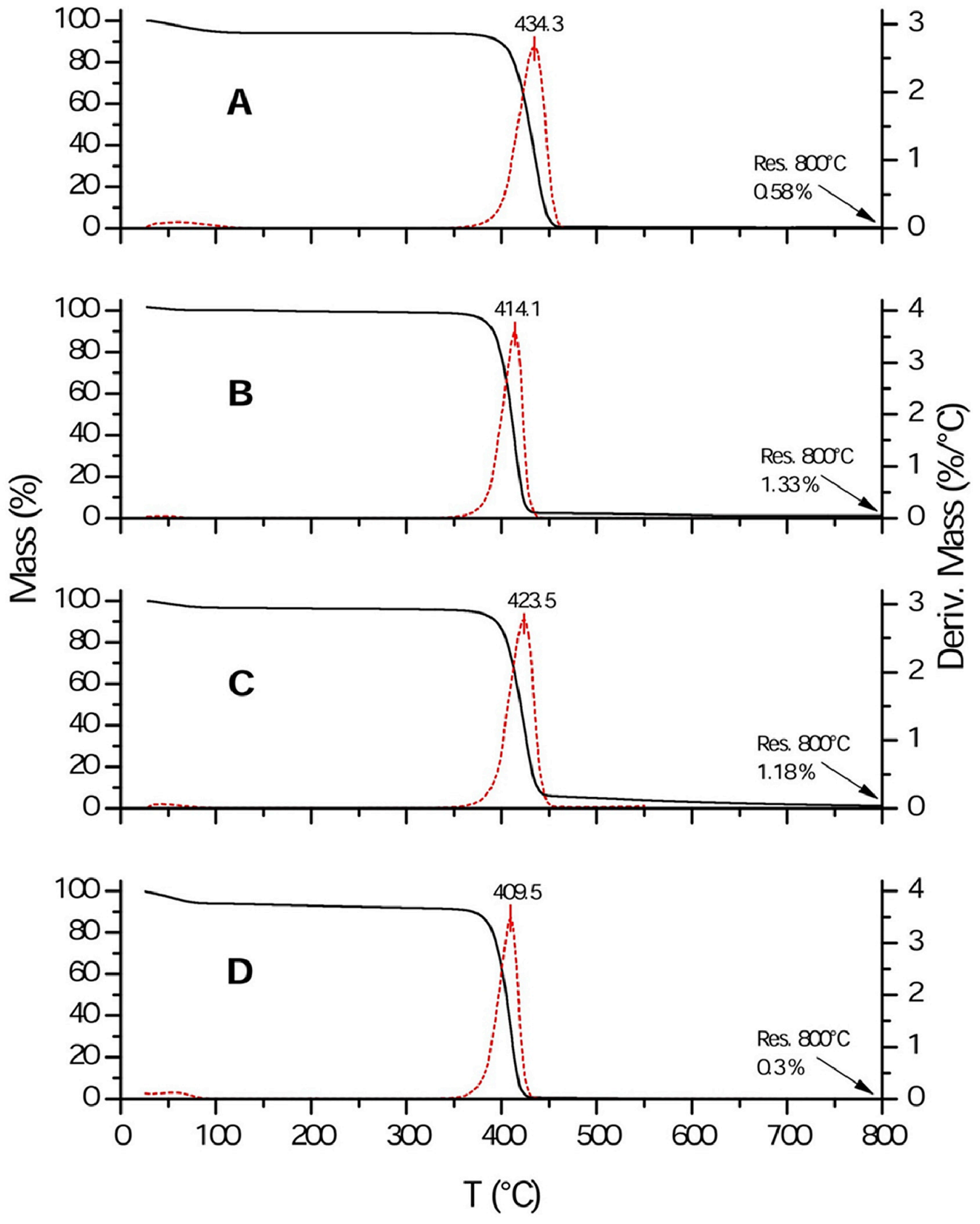

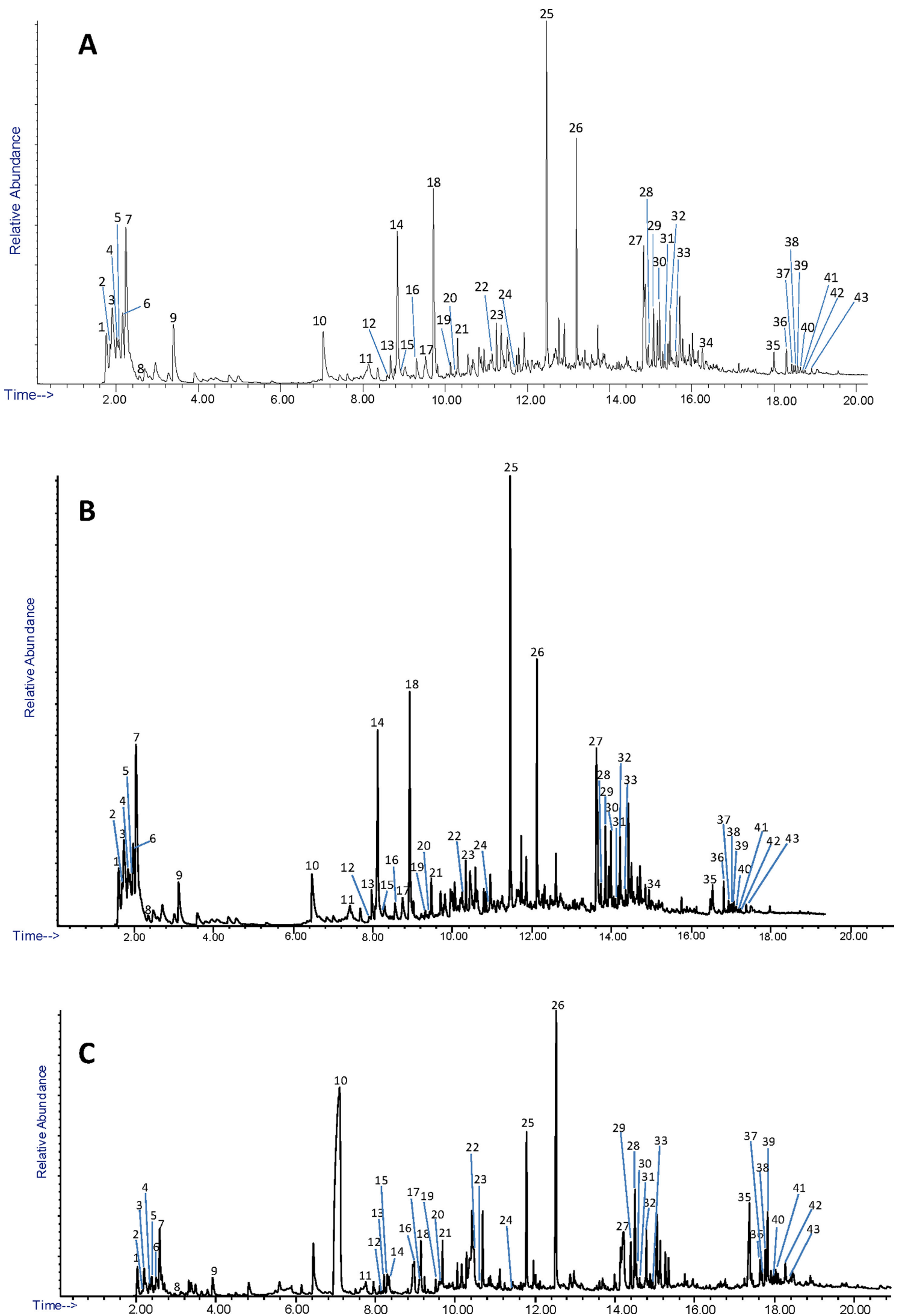
$627 \quad$ Fig 3

628
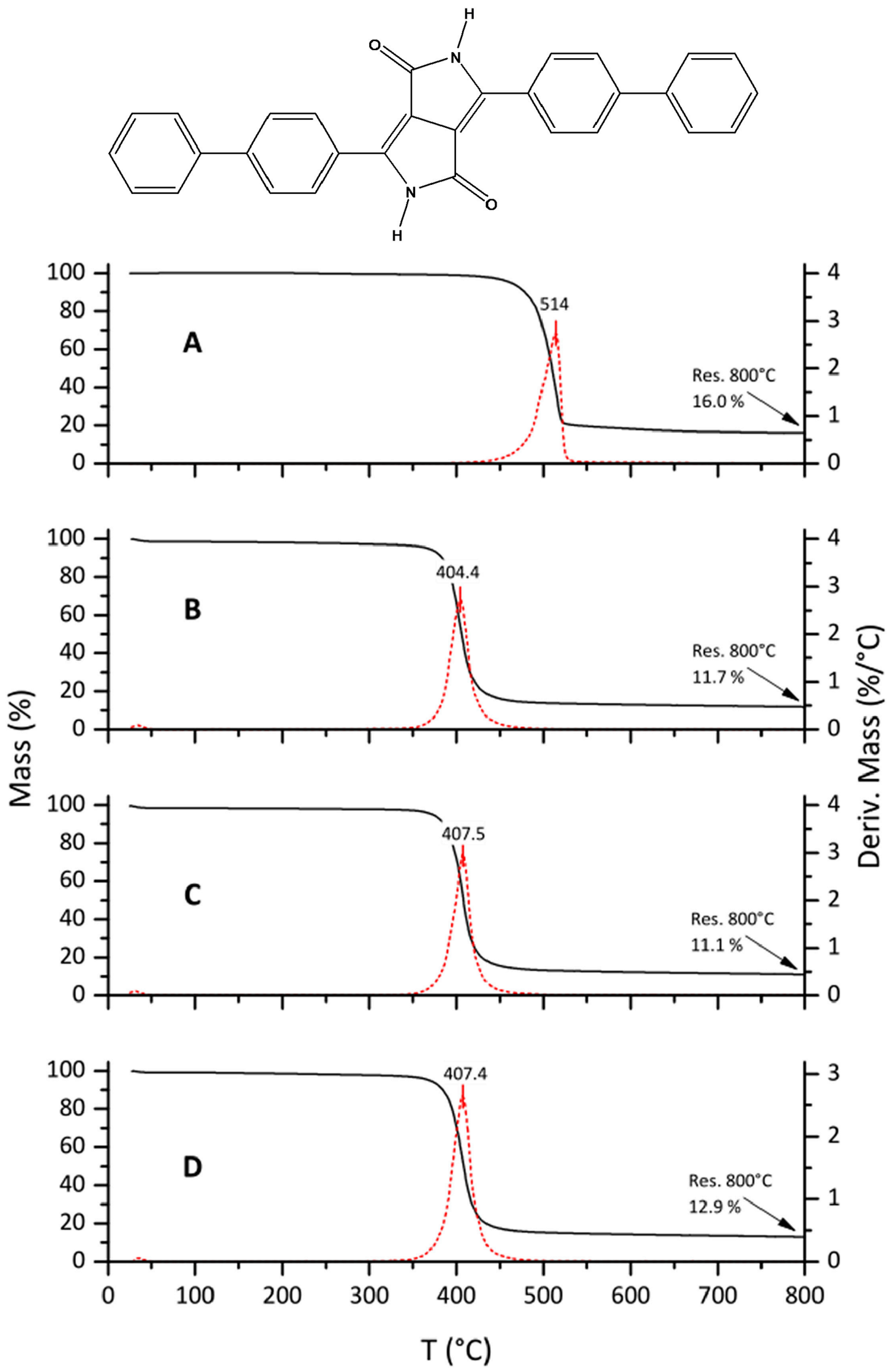

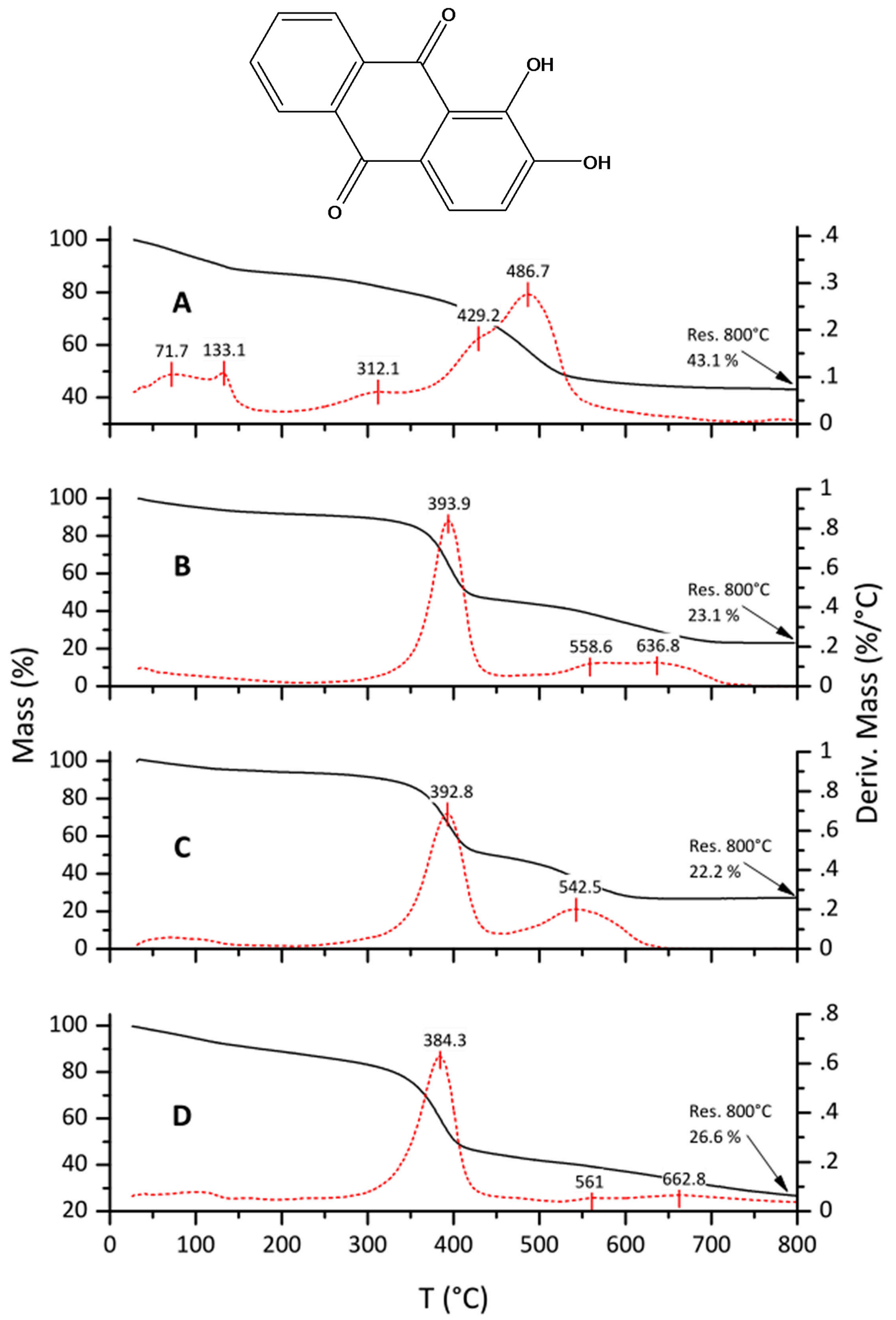

633 

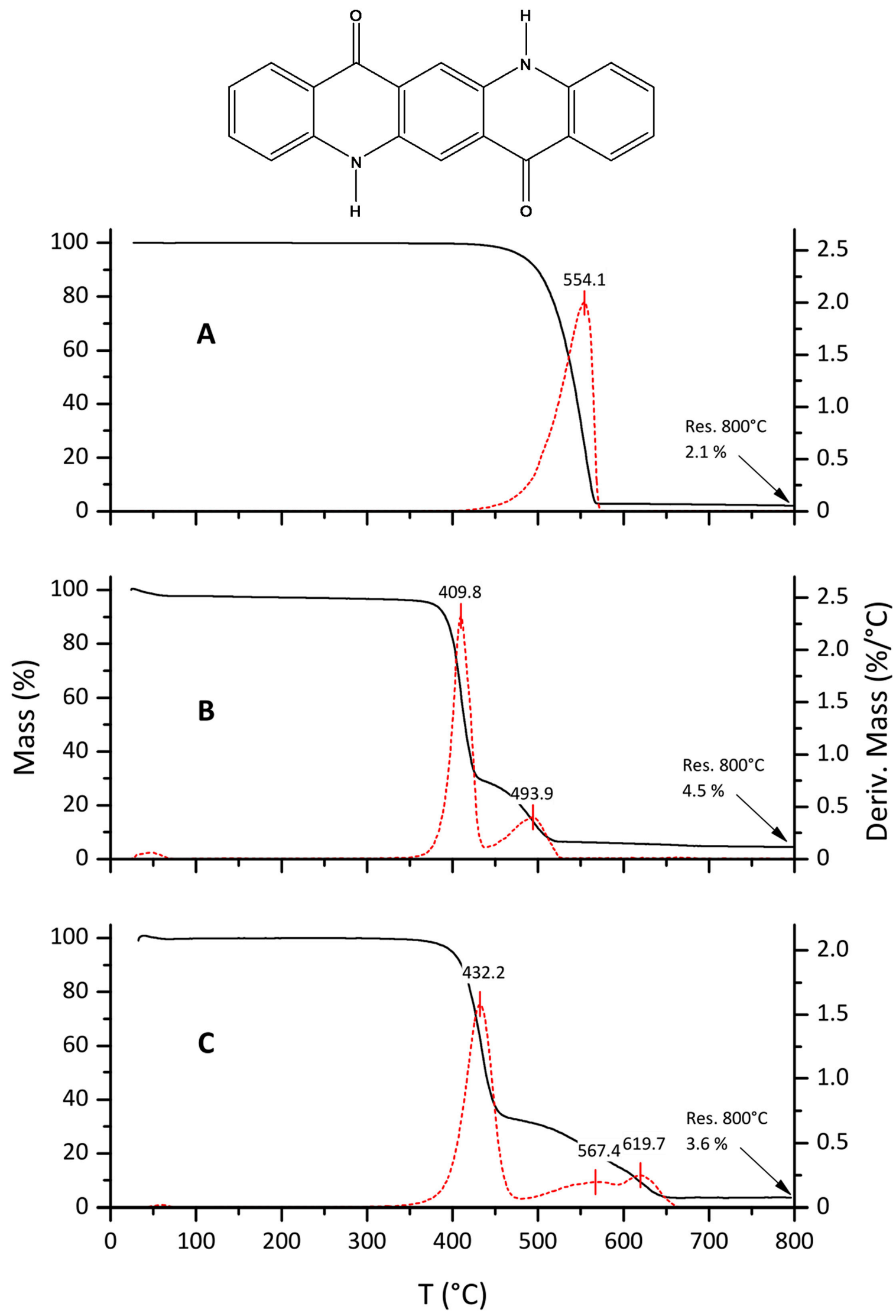
$638 \quad$ Fig 6

639

T (\%)

640

641

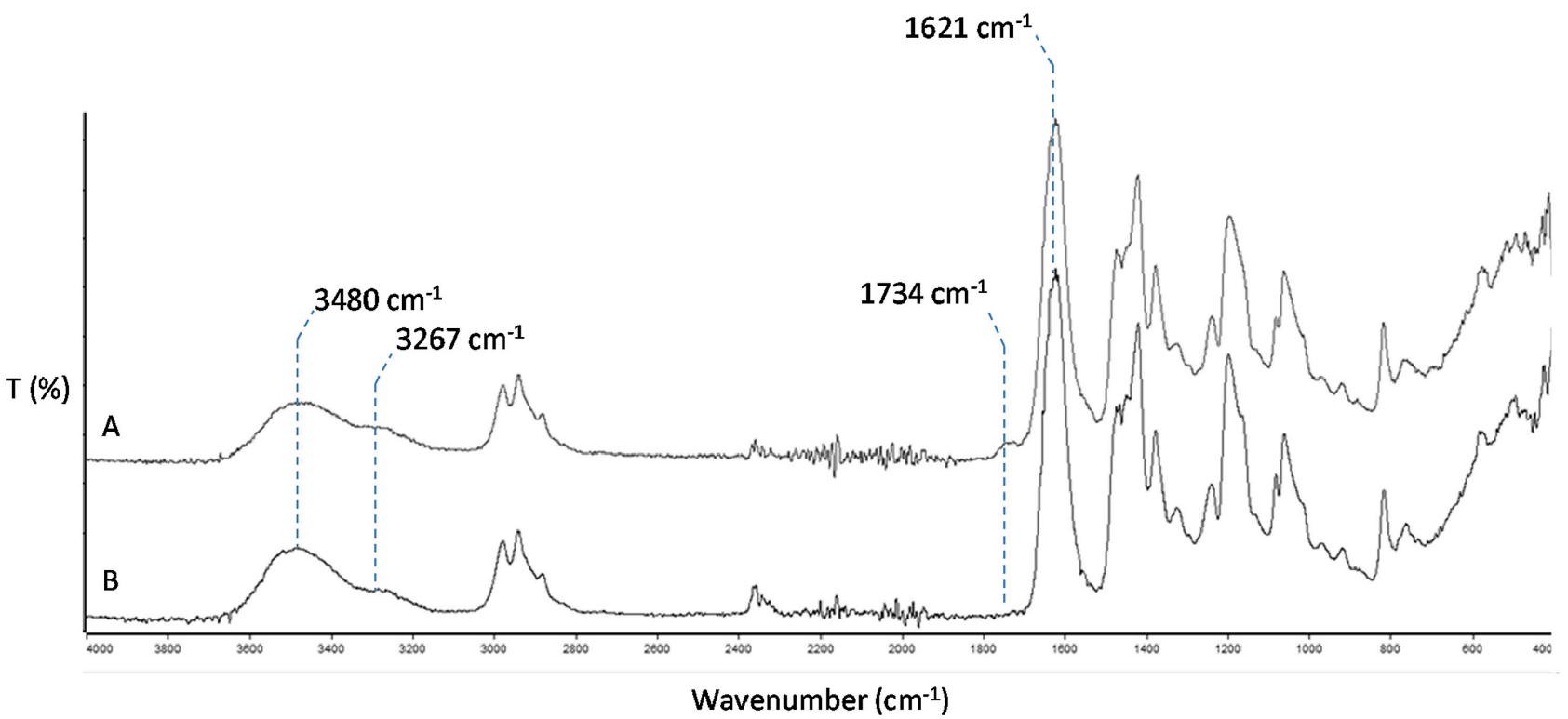



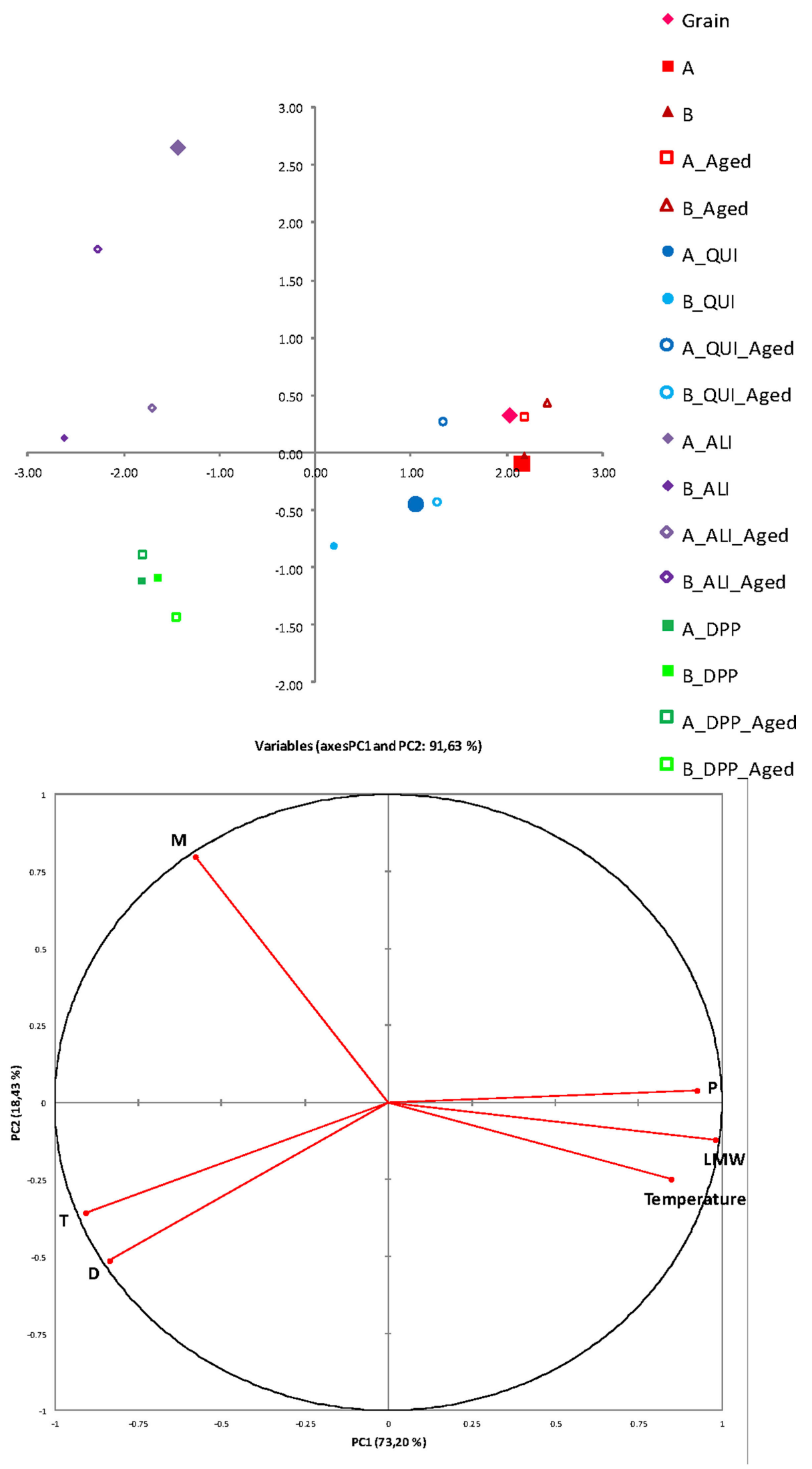
645 Table 1. Compounds identified in the Py-GC/MS chromatograms of Aquazol 500 paint layers. The 646 pyrolitic products were classified into the following five groups: low molecular weight molecules 647 (LMW), propionamide and related alkylated structures (P), monomer and related alkylated structures 648 (M), dimer and related alkylated structures (D), trimer and related alkylated structures (T) [13].

\begin{tabular}{|c|c|c|c|}
\hline Peak number & $\mathbf{m} / \mathbf{z}$ & Assignment & Classification \\
\hline 1 & 56 & Isobutene & LMW \\
\hline 2 & 57 & Isobutene-amine & LMW \\
\hline 3 & 57 & Isocyanatomethane & LMW \\
\hline 4 & 67 & 2-butene-nitrile & LMW \\
\hline 5 & 71 & Unknown & LMW \\
\hline 6 & 71 & Isocyanatoethane & LMW \\
\hline 7 & 54 & Propane-nitrile & LMW \\
\hline 8 & 82 & 2-methyl-butane-nitrile & LMW \\
\hline 9 & 86 & 3-pentanone & LMW \\
\hline 10 & 99 & Monomer (M) & $\mathrm{M}$ \\
\hline 11 & 73 & Propionamide $(\mathrm{P})$ & $\mathrm{P}$ \\
\hline 12 & 107 & 2-ethyl-pyridine & LMW \\
\hline 13 & 108 & Ethyl-pyrazine & LMW \\
\hline 14 & 111 & $\mathrm{P}+\mathrm{CH} 2 \mathrm{CH} 2 \mathrm{CH} 3$ & $\mathrm{P}$ \\
\hline 15 & 87 & $\mathrm{P}+\mathrm{CH} 3$ & $\mathrm{P}$ \\
\hline 16 & 101 & $\mathrm{P}+\mathrm{CH} 2 \mathrm{CH} 3$ & $\mathrm{P}$ \\
\hline 17 & 101 & $\mathrm{P}+\mathrm{CH} 2 \mathrm{CH} 3$ & $\mathrm{P}$ \\
\hline 18 & 113 & $\mathrm{M}+\mathrm{CH} 3$ & $\mathrm{M}$ \\
\hline 19 & 115 & $\mathrm{M}+\mathrm{CH} 3$ & $\mathrm{M}$ \\
\hline 20 & 125 & $\mathrm{M}+\mathrm{CH} 2 \mathrm{CH} 3$ & $\mathrm{M}$ \\
\hline 21 & 127 & $\mathrm{M}+\mathrm{CH} 2 \mathrm{CH} 3$ & $\mathrm{M}$ \\
\hline 22 & 127 & $\mathrm{M}+\mathrm{CH} 2 \mathrm{CH} 3$ isomer & $\mathrm{M}$ \\
\hline 23 & 125 & $\mathrm{M}+\mathrm{CH} 2 \mathrm{CH} 3$ isomer & $\mathrm{M}$ \\
\hline 24 & 155 & $\mathrm{CH} 3 \mathrm{CH} 2+\mathrm{M}+\mathrm{CH} 2 \mathrm{CH} 3$ & $\mathrm{M}$ \\
\hline 25 & 152 & Sesquimer M2-CH2CH2CH3 & $\mathrm{M}$ \\
\hline 26 & 154 & Sesquimer M2-CH2CH2CH3 & $\mathrm{M}$ \\
\hline 27 & 186 & $\mathrm{M} 2-\mathrm{CH} 3$ & $\mathrm{D}$ \\
\hline 28 & 200 & Dimer (M2) & $\mathrm{D}$ \\
\hline 29 & 198 & Dimer (M2) & $\mathrm{D}$ \\
\hline 30 & 212 & $\mathrm{M} 2+\mathrm{CH} 3$ & $\mathrm{D}$ \\
\hline 31 & 196 & Dimer (M2) & $\mathrm{D}$ \\
\hline 32 & 226 & $\mathrm{M} 2+\mathrm{CH} 2 \mathrm{CH} 3$ & $\mathrm{D}$ \\
\hline 33 & 224 & $\mathrm{M} 2+\mathrm{CH} 2 \mathrm{CH} 3$ & $\mathrm{D}$ \\
\hline 34 & 254 & $\mathrm{CH} 3 \mathrm{CH} 2+\mathrm{M} 2+\mathrm{CH} 2 \mathrm{CH} 3$ & $\mathrm{D}$ \\
\hline 35 & 281 & $\mathrm{M} 3-\mathrm{CH} 3$ & $\mathrm{~T}$ \\
\hline 36 & 285 & $\mathrm{M} 3-\mathrm{CH} 3$ & $\mathrm{~T}$ \\
\hline 37 & 297 & Trimer (M3) & $\mathrm{T}$ \\
\hline 38 & 297 & Trimer (M3) & $\mathrm{T}$ \\
\hline 39 & 311 & $\mathrm{M} 3+\mathrm{CH} 3$ & $\mathrm{~T}$ \\
\hline 40 & 323 & $\mathrm{M} 3+\mathrm{CH} 2 \mathrm{CH} 3$ & $\mathrm{~T}$ \\
\hline 41 & 325 & $\mathrm{M} 3+\mathrm{CH} 2 \mathrm{CH} 3$ & $\mathrm{~T}$ \\
\hline 42 & 355 & $\mathrm{CH} 3 \mathrm{CH} 2+\mathrm{M} 3+\mathrm{CH} 2 \mathrm{CH} 3$ & $\mathrm{~T}$ \\
\hline 43 & 355 & $\mathrm{CH} 3 \mathrm{CH} 2+\mathrm{M} 3+\mathrm{CH} 2 \mathrm{CH} 3$ & $\mathrm{~T}$ \\
\hline
\end{tabular}


Table 2. Characteristic absorption bands in FT-IR spectrum of Aquazol 500.

\begin{tabular}{|l|l|}
\hline \multicolumn{1}{|c|}{ Absorption bands $\left(\mathbf{c m}^{-\mathbf{1}}\right)$} & \multicolumn{1}{|c|}{ Vibrational modes } \\
\hline 3483 & O-H (moisture, adsorbed water) \\
\hline $2971,2940,2880$ & C-H stretching (CH2, CH3 groups) \\
\hline 1629 & C=O stretching (tertiary amide) \\
\hline 1473 & C-N amide stretching \\
\hline $1418,1375,1321$ & C-H bending (CH2, CH3 groups) \\
\hline $1241,1192,1061$ & C-C stretching (polymer chain) \\
\hline
\end{tabular}

